Article

\title{
The Role of Evidence-Based Practice in German Special Education-State of Research and Discussion
}

\author{
Yvonne Blumenthal ${ }^{1,2, *}$, Bodo Hartke ${ }^{2}$ and Stefan Voß ${ }^{3} \mathbb{D}$ \\ 1 Department of Special Education, University of Rostock, 18055 Rostock, Germany \\ 2 Department of Education, University of Greifswald, 17489 Greifswald, Germany; \\ bodo.hartke@uni-rostock.de \\ 3 Department of Education and Psychology, Freie Universität Berlin, 14195 Berlin-Dahlem, Germany; \\ stefan.voss@fu-berlin.de \\ * Correspondence: yvonne.blumenthal@uni-rostock.de
}

Received: 28 March 2019; Accepted: 13 May 2019; Published: 16 May 2019

\begin{abstract}
This paper reviews the discourse on the concept of evidence-based special education in Germany. A short overview of the current situation in regard to available evidence-based educational materials for schools in Germany and the USA is given. Critical objections on the topic within Germany will be outlined thereafter. With these in mind, a discussion on the described points of criticism will follow in closing. Overall, the concept's essential elements, such as the social and internal evidence, are not given sufficient consideration.
\end{abstract}

Keywords: evidence-based practice; external evidence; social evidence; internal evidence; practice-based evidence; educational decisions

\section{Introduction}

In the discussion in Germany about the principles of special educational practice, the term "evidence-based practice" (EbP) is used in connection with the status of special education, its concepts, and its approaches [1-3]. The central result of these discussions is the demand for an empirical and theoretical assurance for special educational practice and initial review papers. Consequently, the international debates on evidence-based medicine $(\mathrm{EbM})$ standards and their analogies in psychology and education as well as within the special educational discussion in Germany deserve consideration. As a result, the use of external evidence during the decision-making of EbM when treating patients [4] has also been widely accepted and adopted by special educators. In this paper, we used the term actor for every person involved in educational decision-making and instructional actions. In Germany, this refers to general education teachers and special educators as well as educational assistants for specific children with special educational needs or school psychologists. An educational action in this context relates to all decisions made by the actors regarding the selection of teaching materials and instructional methods for the whole class, but also specific interventions to differentiate and individualize for individual students.

These actions should be determined based on findings from single case studies as well as results from scientific efficacy studies that are comparable. According to Hillenbrand [5], scientists generate research results to be reviewed according to their effectiveness and professionals develop a practice based on knowledge about existing research results and can implement a specific action based on an individual situation. Even though the core construct of evidence-based actions is accepted according to many experts with scientific and practical backgrounds [6], a critical discussion around this construct within Germany has pointed out many objections. Thus, the objective of this paper is to provide 
information on the current standing around this discussion and in doing so, to look at the chances and limitations of an orientation around the EbP construct within German special education.

In this paper, we summarize the construct of EbP and explain terms such as internal, social, and external evidence. We describe the debates held in Germany around evidence-based special educational work, which are strongly oriented to developments in the USA. For this reason, we provide a summary of the EbP discussion in the USA. We discuss the objections toward the EbP concept to determine useful special educational practices, taking the results of efficacy studies and educational considerations into account. We base the representations and arguments on a perspective that emphasizes the strengths of efficacy studies for special educational theory formation and practice, but also considers its limitations.

\section{The Construct "Evidence-Based Practice (EbP)"}

Almost all scientific discussion around EbP in German special education has focused primarily on the effectiveness of a special educational action through its scientific evidence (external evidence). This approach, however, falls short with regard to the definition of evidence-based medicine (EbM) provided by Sackett et al. [7] for EbM decisions for treatment or therapeutic action based on the following three evidence aspects $[8,9]$ :

- External evidence (i.e., currently valid scientific and empirical proof of efficacy);

- Internal evidence (i.e., individual knowledge and experience of the treating person); and

- Social evidence (i.e., preferences, experiences, and values of the person affected by the treatment).

Applied to special educational contexts, evidence-based actions should be based on current and valid scientific results (external evidence), with consideration of the expertise of educational staff (internal evidence) as well as the specific needs of a student or their parent/guardian (social evidence). The aim is to find the best possible and most suitable actions for the individuals involved and to verify the effectiveness of these actions continuously. Only when taking these aspects into account can evidence-based actions take place.

Aside from the core idea and goals, EbM and EbP share similarities for the selection of a special educational action. To decide on a suitable action, we recommend a gradual approach. The concrete number of stages in an evidence-based decision-making process usually varies between five and 10; with regard to content, however, they coincide in essence [7,10-15]. Figure 1 summarizes a possible procedure for the evidence-based decision-making process, which we will explain, by taking special educational aspects into account [8].

We started by identifying the problem and understanding the parameters for the student or class within special education. Then, we developed a precise question (i.e., a "well-built (clinical) question" [15]), as this question laid the foundation for all subsequent decisions. The question was precise and verifiable and included specifics about prevention or intervention and objectives. Furthermore, this question defined the affected group (e.g., age span, and gender), the situation, and the underlying problem. The question also provided the basis for the literature review [14]. A detailed and, preferably, objective analysis of an individual situation and its conditions and needs must also take place [12].

External evidence is considered the supporting pillar of EbP and is often portrayed as the only type of evidence to consider when designing a special educational program. External evidence is often relied upon, because internal and social evidence is considered too error-prone. The value of the experience of experts involved in the decision and intervention process, however, is not proof enough for the effectiveness of an action. Unsystematic everyday observations, assumptions of efficacy, retrospective estimates, and successful isolated cases can easily lead to an over-generalization with regard to the evidence for an action. This is why it is essential that external evidence is based on reliable scientific research conforming the efficacy of the considered actions. Research demonstrating empirical proof of efficacy is very complex, and for this reason, quite a few individual contributions 
from different sources (e.g., manuals, articles from reviewed journals, and databases) need to be compiled. This is followed by a critical analysis of the published research results and the conclusions drawn from research. To assess these results, the actor needs adequate background knowledge on how to assess the quality of study designs as well as skills to interpret statistics. Additionally, the actor must critically evaluate the published efficacy studies for generalizability or probability of success, in terms of respective actions that may occur under different circumstances. There are, to some extent, indications as to when a respective action is unfavorable. Therefore, it is important to identify and take these circumstances into account.

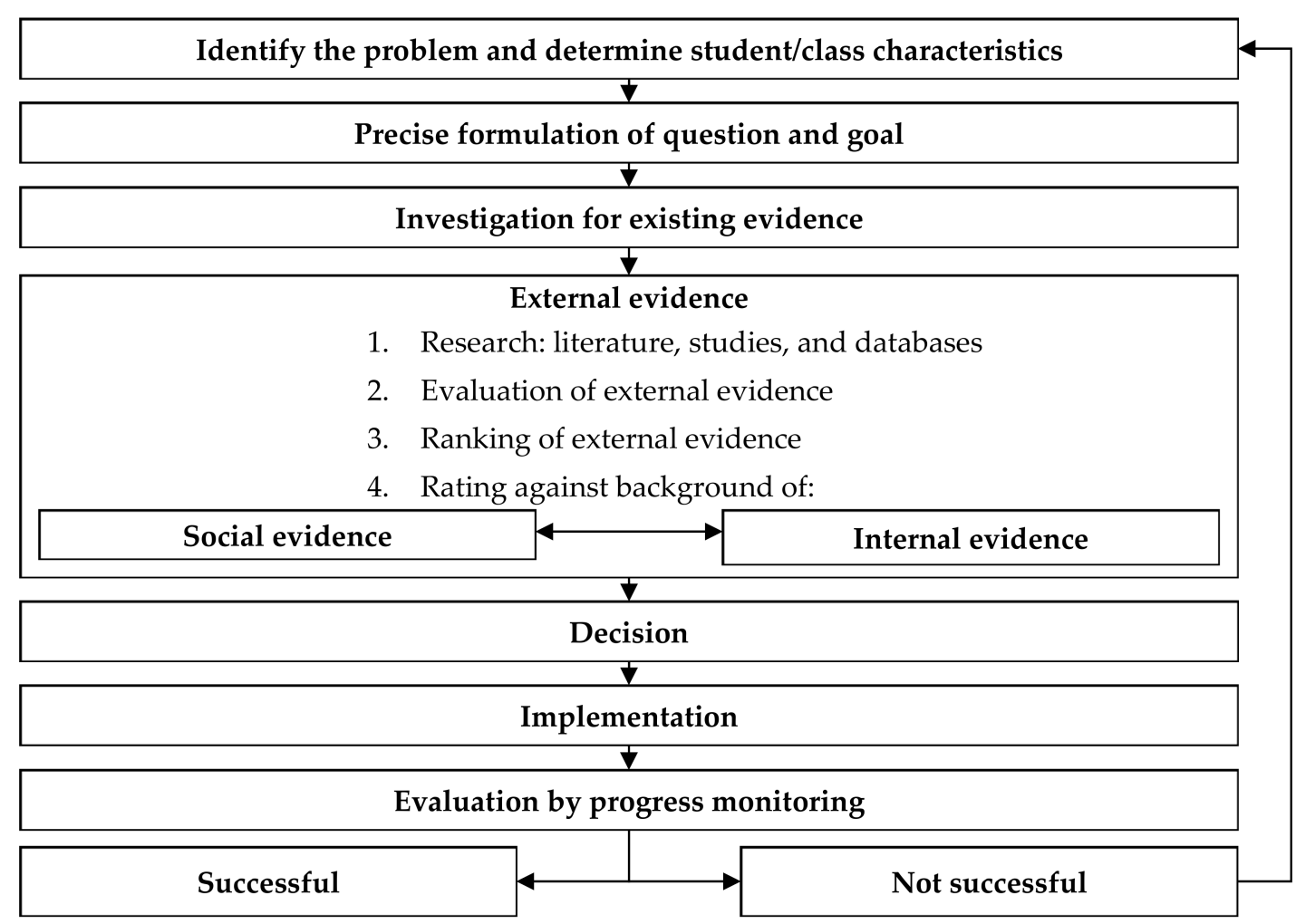

Figure 1. Procedure of an evidence-based decision-making process (see [8] (p. 410)).

In terms of social evidence, the values and experiences of affected students and to some extent their relatives should be the main focus of consideration. Conversations and interviews with affected individuals make it possible to establish measurable goals of intervention, so these goals can be evaluated [13]. It is important that any actor treating these individuals anticipates the individual's needs and will allow the individual to actively be a part of the decision-making process to form a balanced partnership.

Within the educational context, the choice of actions needs to be examined to ensure that actions are, for example, designed to be child-friendly and are suitable for a specific learning group or a special training group. Moreover, team coaching and direct conversations with the child are essential to establish explicit and measurable goals.

The internal evidence of an action is guaranteed through therapeutic or educational expertise (i.e., work experience and professional knowledge). Here, the actor needs to decide which actions suit their knowledge and capabilities (positive self-efficacy experience).

Although not explicitly recognized, another relevant source of evidence is the expertise of the actors, also known as "practice-based evidence". In this way, more confidence can be placed in colleagues with positive experiences compared to external scientific studies [16].

The following example illustrates the interaction between the three sources of evidence. We assume that effective reading-competence training requires a high degree of parent involvement through 
regular reading at home. The educator, as the source of internal evidence, experiences the following situation: parents lack the willingness to cooperate with the school and, as a result, the child experiences the collaboration between educators and parents as stressful (social evidence). In this case, the choice of action would consequently fall on the second-best training within the ranking of external evidence; this training would require less parental involvement.

As shown in Figure 1, the EbP process is not exhausted by the choice of a suitable action, but rather includes a formative evaluation of the applied action as well as possible adaptations. The decision about whether the action is effective is based on child-level performance data. Furthermore, the actor must decide about whether to keep, modify, or cancel the action (see also internationally valid taxonomy of Fuchs, Fuchs, and Malone [17]). Therefore, EbP is not a static construct, just as evidence is not static; it is a product of current research and should therefore be critically reflected and updated regularly, if necessary.

\section{The Present Discussion on Evidence-Based Practice in the USA}

Since 2001, the USA has required an increased use of research-based instruction, according to its No Child Left Behind (NCLB) Act. This act demands the support of all students through actions verified through scientific research and that have been proven effective through high-quality studies $[18,19]$. The law formulates the requirements for scientific-based actions evaluated by strict, systematic, and objective procedures. To meet the EbP criteria of the NCLB Act, the following points must be met:

- "Employ systematic, empirical methods that draw on observation or experiment;

- Involve rigorous data analyses that are adequate to test the stated hypotheses and justify the general conclusions;

- Rely on measurements or observational methods that provide valid data across evaluators and observers, and across multiple measurements and observations; and

- Be accepted by a peer-reviewed journal or approved by a panel of independent experts through a comparatively rigorous, objective, and scientific review" [20] (p. 1).

In the American discussion regarding EbP, the term research-based can therefore be regarded as a synonym for the term evidence-based. However, it refers exclusively to external evidence. In this context, various websites by the US government or other independent agencies within the USA have been developed to spread evidence-based actions and to support the implementation of actions such as

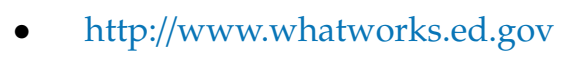

- http://www.findyouthinfo.gov

- http://www.evidencebasedprograms.org

- $h t t p: / / w w w . b e s t e v i d e n c e . o r g$

- $\quad$ https://evidenceforessa.org

\section{The Present Evidence Basis in Germany}

While the selection and implementation of evidence-based educational practice within the Anglo-Saxon literature has been discussed and operationalized for some time [21,22], the debate around EbP in Germany-apart from the medical context-has also been established within the psychological and psychotherapeutical fields, but less so within the educational and special educational contexts. Despite available references within early literature on evidence-based special educational papers [1-3,23], distinct meaning has only been given to this construct during the past decade.

Fundamental differences from the international discourse result in differing definitions of the terms "evident" or "evidence". In the USA, the terms are interpreted as information indicating an action is proven valid. In German-speaking countries, the term is used to describe "obviousness" and, in this sense, does not require further examination. This means opposing terms are being used to describe 
the same construct [24]. With the rise of scientific discussions around the topic of evidence-based educational actions, the understanding of the term EbP grows closer to its meaning in the USA.

Another difference is that the discussion about EbP in Germany mainly refers to external evidence. This one-sided point of view on eEbP has been criticized [8]. Consequently, criteria have been systematically categorized for the assessment of scientific evidence on teaching and support programs within special educational literature [1-3,23]. Thus, the following minimal requirement needs to be met: the material, approaches, or methods are only "recommendable under certain conditions" [5] (p. 17) or "potentially effective" [1] (p. 9) if they are scientifically proven and if there are indications on effectiveness that are documented in empirical and methodological studies. The investigated effects should be published through scientific literature. It would be desirable for the choice of teaching material to be empirically verified. Evidence-based practice can only be defined as such if the material is underpinned by a scientific model and has been evaluated by more than one well-designed control group study [1]. Considering the above, we identified some training programs in Germany complying with the minimum standard of evidence:

- $\quad$ To support learning in general (e.g., [25]);

- To support arithmetical competences in primary-school age children (e.g., [26]);

- To support verbal or textual skills (e.g., [27]);

- To support language development (e.g., [28]);

- To support prosocial skills (e.g., [29]);

- To support behavioral problems (e.g., [30]).

At this point in time, the basis for available evidence-based concepts in Germany is significantly poorer than in the USA. Like the USA, available evidence-based materials are mainly available at the primary school level. At this point in time, there is only one database evaluating approaches for the prevention of violence, addiction, crime, and behavioral problems regarding their efficacy [31].

While different training and therapy programs in Germany are available where efficacy has been proven within the scope of systematic studies, there is a lack of teaching textbooks with a evidence-base. This circumstance contradicts the growing need for EbP in Germany. Until tangible proof for the efficacy of German textbooks is present, scientific criteria need to be used to decide which instructional materials should be implemented. Consequently, one has to synthesize normative, scientific, and empirical aspects from several studies. Within this framework, one will find insights and assumptions of empirical educational research including special education and general didactics as well as cognitive, developmental, and educational psychology for all educational departments. For the scientific reasoning of choice for textbooks, and the corresponding material and support programs in Germany, Voß, Sikora, and Hartke [32], as well as Diehl, Voß, Sikora, and Hartke [33], created lists of criteria based on scientific knowledge. These were comprised of eight general criteria, which helped determine whether an investigated material complied with them or not:

1. Mediation of subject related and non-subject related competencies;

2. Motivated and reasonable organization;

3. Systematic and logic grounded progression of learning units with clear goals;

4. Plurality of teaching methods and principles;

5. Consideration and support for different learning techniques;

6. Enabling and using feedback;

7. Suitability for work within a heterogenic learning group;

8. Meaning and support for the process of repetition.

These general aspects as well as subject specific indications need to be taken into consideration when selecting textbooks, materials, as well as supporting programs. 
All general criteria are operationalized by several differentiated statements regarding the material. The objective is to help the actor critically evaluate a new textbook or reflect on the material that has been used. The user should also be able to compare materials. Within the medical field, expert opinions constitute a rather low form of evidence, which is only utilized if information from a higher level of evidence is not available [34]. The above list of criteria does not intend to cancel the existing standards of evidence; rather, it serves as a transitional tool until the demand for evidence-based teaching material can appropriately be met.

\section{Present Criticism of Evidence-Based Education in Germany}

In general, effective support in special education is not disputed by critics of evidence-based practice. The gain of empirical research for effective educational actions and the resulting dependencies are questioned. Hereafter, some central critical objections by Ahrbeck and colleagues [35] are summarized:

- The EbP construct goes hand-in-hand with a reduction of education with regard to its measurable outcome. In particular, measuring school success is essential. An over-focus on external evidence would lead to an exclusion of normative and socio-critical claims from the educational discourse. This reduction leads to a loss of goal orientation, and topics such as interactions with the socially disadvantaged take a backseat. Education would reduce itself to a provider and deliverer of knowledge for an existing education system [36];

- Special education holds a position that the best possible research evidence will be used as a foundation for decisions in practice. The question remains, however, whether the so-called "gold standard" as the highest level of evidence can be implemented within the educational field [36].

- EbP excludes insights into unexpected individual cases and the handling of unusual educational situations, in which, for example, psychoanalytic or phenomenological knowledge and thinking would be necessary [37];

- The reductionist approach of EbP results in humanistic and critical educational content being excluded from the training of teachers. This is problematic, because educational competence is distinguished by knowledge on and through dealing with uncertainty [38]. A university education must promote general abilities like educational attitudes, educational tactfulness in accordance with Herbart, and reflexivity. The key role of academic training of educators is not to teach knowledge on empirical evidence, but rather to create educators that can act in educational situations, despite uncertainty. Personality is more important than knowledge on technology [39];

- Applicable high standards of external evidence do not consider problems regarding the external and the ecological validity of empirical studies. As educational situations are very complex with an uncontrollable multilevel structure of impactors and the interactions between them, transfers of study results to other situations are not feasible [36];

- Researchers that follow the EbP construct need a substantial amount of financial means for their work and thus are dependent on third-party donors, usually governmental bodies, who have a controlling instrument in educational science. Additionally, researchers are forced to utilize research methods that have mostly been used by other social scientists; in doing so, they create another dependent relationship with further consequences such as the loss of "native" concepts and methods. With EbP, education almost abolishes itself and degenerates to a "repair facility" of children described as being deficient [39];

- In addition to the loss of the core educational thinking and acting, EbP also damages the quality of scientific research itself. For its dominance, the EbP would oppose interpretative, non-data-driven scientific approaches (hermeneutic research). Without hermeneutic research approaches, the discussion on data or research results would be less profound [35].

The above summary of the discussion on objections to EbP contains serious arguments and fears, which will be discussed below. 


\section{Discussion on the Objections toward the EbP Construct}

The statements on the approach of EbP in Section 2 explain that the construct is highly complex and demands professional requirements from the actors. The construct does not deprive professionals of any decision, but supports the decision-making process through rationally based actions and permits leeway for decisions. They exist particularly in the following:

- The development of the "well-built question";

- The choice of actions, taking internal and social evidence into account; and

- The choice of criteria for evaluation or evaluation methods.

We now discuss the objections to EbP described in Section 5 in a constructive way.

\subsection{Reduction of Educational Reality to the Measurable (Usually School Achievement); from Education to a Service}

Within the EbP construct, complex reductions are taking place. Screening methods are used to identify children with special needs who require additional support. For the development of a "well-built question", school performance is often central. However, is not this sensible or even necessary in many special educational problem situations? Why is it problematic, if, for example, specific difficulties are identified, a child receives the necessary support, and its success is tested? It would be problematic if the focus of an educational action on a specific problem became so overwhelming that other educational goals lost relevance. Should an evidence-based action contradict an educational intention to some extent, actors must take that into account during the decision-making process and, if possible, even prevent it. It would be fatal if acting educators did not include specific supporting elements in a humanistic educational concept, that intended to develop autonomical and competent children.

\subsection{Pretense of Certainty in Action, Where Uncertainty Prevails Due to the Complexity and a Lack of External Validity of Research Results}

EbP strives toward increasing the probability of effective educational actions. Empirical knowledge in education is not one-dimensional (i.e., precise knowledge of causal relationships with the certainty that $\mathrm{A}$ is followed by B). Research methodology within empirical educational science is usually concerned with testing contextual or efficacy hypotheses with a conditional probability. The transfer of results from empirical studies to individual cases always needs to be critically evaluated. Empirical research does not offer more suggestions on probabilities for educators. It would be regrettable, however, if actors used the EbP construct without including this in their actions. However, it would be just as unfortunate, or even irresponsible, if the chances of orientation to empirically proven measures were ignored in practice.

\subsection{The Question of Whether External Evidence in Education that is Based on a "Gold Standard" is at All Valuable or Reachable}

The "gold standard", combined with common evidence hierarchies (e.g., the Oxford Scale [34]), provides the highest level of scientific evidence due to randomized controlled trials. One question that needs to be asked is whether the relevant target groups needed for randomized studies of students with special educational needs can be attained. There are many sub-groups with special needs who show diverse student profiles and cannot be uniformly defined due to different definitions and classifications. Additionally, a school setting is highly complex and cannot be compared to laboratory situations where influencing factors can be systematically controlled. An ecologically valid proof of evidence only seems possible through a "quasi-experimental field study." There are more reasons for speaking against an overly narrow orientation towards evidence hierarchies from the medical field. Furthermore, it should be kept in mind that, even in the case of existing evidence, in the sense of a "gold standard" for a specific action, one-to-one transference of this action into practice (to ensure success of action) is hardly possible 
within a special educational context. A specific adaptation to transfer to an individual educational situation is often expected to meet the needs of the children. In the sense of an idiosyncratic problem solution, standardized evidence-based measures are relevant insofar as they should be adapted to the individual case and the given conditions while maintaining their central core elements $[9,17,40]$. Considering this, the importance of single-case studies as a methodological response compared to a heterogenous circle of individuals is growing within special education [41].

\subsection{Dependencies on Third-Party Donors with Vested Interests and the Loss of Independence as Well as a Critical Attitude Towards Educational Practice}

An EbP requires empirical research. This is only possible when research funds are raised. The danger of this could be the control of research through funds, which truly constitutes a serious problem considering the lack of funds for research in special educational research facilities. Some funds are accessible through different social institutions (e.g., foundations, societies, and federal and state ministries). Thus, it is also a matter of social discourse about the research funds that will be made available. Nevertheless, the problem remains that the loss of scientific freedom through third-party funding is evident and needs critical examination by educational scientists.

6.5. Ignoring Non-Empirical Educational Scientists and, in Doing so, Significant Information that Influences Personality Development of Educators, Results in the Loss of Interpretative Reflexive Educational Competence

Courses on historical, education-philosophical, philosophical-ethical, epistemological, social, and other questions are indispensable during special educational studies. Normative aspects as well as the social relativity of special education, and issues on special educational identity formation and attitudes, are highly relevant during the course of study. Except, why does the focus on the results of special educational efficacy research lead to a loss of the above-mentioned social sciences and humanities aspects during teacher training? It is certainly possible and useful to look at research from different epistemological perspectives and consider the methodological works of different scientists. Only mutual acceptance and appreciation between representatives of different educational approaches can lead to a well-founded curriculum (which entails multi-disciplinary aspects and is cross-directional) in educational sciences. Many universities have traditions that teach different paradigms of educational science and its methods, which should be continued.

\subsection{Exclusion of Findings within Unexpected Cases-Loss of Reflexive Abilities in Complex Educational Situations and thus a Crucial Element of Education (i.e., Making Personal Decisions within Educational Settings)}

A loss of reflexive personal decisions within educational situations would be a fatal development. Numerous studies (e.g., [42]) have proven that the development of human beings takes place in social contexts through personal relationships. A depersonalized education would be a deprivation! Programs do not educate, but rather people educate people. In particular, special education defines itself through the responsible actions of individuals for and with individuals with or at-risk for special needs profiles. In this respect, empathy, in the sense of a sympathetic understanding, compassion, and caring, as well as the reflection of individual educational situations including unexpected cases and options for action, constitutes elements of special education, and thus needs to be part of a special education course. On the other hand, professional education is concept-based, and concepts should be evaluated. Thus, questions of decision-making situations arise that can be clarified rather reflectively, for example, through considering arguments or through self-reflection as well as decision-making processes that are based on external, internal, and social evidences or through a combination of several problem-solving approaches. Without being able to answer this question, several arguments are in favor of the concept that both reflective abilities and abilities considering finding of efficacy research in special education are of importance. In practice, a combination of both decision paths is useful, at least in some situations. Thus, conceptual-methodical decisions about, for example, teaching concepts 
and methods, elements of classroom management, prevention of violence at schools, etc., are very likely to be made responsibly and in favor of the EbP construct. Individual day-to-day challenges within the educational setting such as the unwillingness of a child to enter the classroom, dealing with bereavement in a child's family, or a conflict in a table group, are to be dealt with educational tact. Actors also need to take several possible courses of action (e.g., possibly also look at the background of research results on behavioral problems, bereavement with children, and conflict moderation) into consideration. Educational challenges are thus only similar to some areas of medical decision-making situations. An authentic personal encounter is "prescription-free." However, it requires professional reflection and individuals that will engage responsibly in special educational processes. The latter already begins with the selection of educational concepts.

\section{Conclusions}

The attempt to map out boundaries as well as opportunities of the EbP construct within German special needs education led to the realization that the construct is highly challenging on many levels. Within research and practice, EbPs demand competent developers and users who do not reduce the EbP construct based on a decision-making technique, regardless of the involvement of others. The conclusion presented here thus follows on from the critically conducted discussion on evidence-based medicine [43]. Contrary to static, generally valid decision-making approaches, more flexible approaches should be chosen that better correspond to individual problem situations and also do justice to multimorbid manifestations. In its application, the EbP construct needs special educators that will take external evidence, internal evidence, and social evidence into account when it comes to the decision-making process. Additionally, rational actions need to be embedded in ethical and socially reflected educational programs. In the absence of such reflective integration of the evidence-based decision-making-process within a democratic education, there is a risk of a reductionist distortion of the EbP construct in favor of various interventions that are separate from each other, yet similar to one another.

When the EbP construct is implanted into a democratic education, it offers the chance to utilize empirical results to increase and ensure the quality of instruction and specific support. The relevance of the EbP construct is made clear when asking yourself the question about alternatives. Neither "eminence-basing", "collective guessing", or "pure intuition-basing" are suitable for the selection of teaching concepts, methods, and materials for students with special educational needs. The EbP construct offers advantages in the consideration of internal, social, and external evidence. On the other hand, without personal decisions and encounters, education is not possible. Reflective and responsible individuals are needed in everyday educational situations.

Desirable in practice are well-founded educational decisions made by special needs educators. This requires different types of evidence as well as educated individuals who engage in educational processes that are motivated, responsible, and reflective. Therefore, a multi-perspective approach in dealing with evidence in educational contexts must be imparted in teacher preparation. This means not only narrowing the view exclusively to external evidence, but also emphasizing the importance of critical-reflective approaches in the scientific discourse. This is a prerequisite for dealing with the EbP construct responsibly and for the personal development of the educators.

Author Contributions: The authors contributed equally to the conceptualization, writing, and revision of this article.

Funding: This research received no external funding.

Conflicts of Interest: The authors declare no conflicts of interest. 


\section{References}

1. Fingerle, M.; Ellinger, S. Sonderpädagogische Förderprogramme im Vergleich. Orientierungshilfen für die Praxis; Kohlhammer: Stuttgart, Germany, 2008.

2. Hartke, B. Schulische Prävention-Welche Maßnahmen haben sich bewährt? Z. Für Heilpädagogik 2005, 56, $470-481$.

3. Nußbeck, S. Evidenzbasierte Praxis-Ein Konzept für sonderpädagogisches Handeln? Sonderpädagogik 2007, 37, 146-155.

4. $\quad$ Sackett, D.L.; Rosenberg, W.M.C.; Gray, J.A.M.; Haynes, R.B.; Richardson, W.S. Was ist Evidenz-basierte Medizin und was nicht? Munchener Medizinische Wochenschrift 1997, 139, 644-645.

5. Hillenbrand, C. Evidenzbasierte Praxis im Förderschwerpunkt emotional-soziale Entwicklung. In Inklusion im Förderschwerpunkt Emotionale und Soziale Entwicklung, 2nd ed.; Stein, R., Müller, T., Eds.; Kohlhammer: Stuttgart, Germany, 2017; pp. 178-215.

6. Hollerwöger-Kellner, G. Evidenzbasierte Leseförderung mit kooperativen Leseverfahren. Eine Mikrostudie aus der Schulpraxis zum Training der Leseflüssigkeit. Z. Für Heilpädagogik 2019, 70, 122-135.

7. Sackett, D.L.; Straus, S.E.; Richardson, W.S.; Rosenberg, W.; Haynes, R.B. Evidence-Based Medicine: How to Practice and Teach EBM; Churchill-Livingstone: London, UK, 2000.

8. Blumenthal, Y.; Mahlau, K. Effektiv fördern-Wie wähle ich aus? Ein Plädoyer für die Evidenzbasierte Praxis in der schulischen Sonderpädagogik. Z. Für Heilpädagogik 2015, 66, 408-421.

9. Torres, C.; Farley, C.A.; Cook, B. A Special Educator's Guide to Successfully Implementing Evidence-Based Practices. Teach. Except. Child. 2012, 45, 64-73. [CrossRef]

10. Dollaghan, C. The Handbook for Evidence-Based Practice in Communication Disorders; Paul H. Books: Baltimore, MD, USA, 2007.

11. Mangold, S. Evidenzbasiertes Arbeiten in der Physio- und Ergotherapie; Springer: Berlin, Germany, 2013.

12. Nußbeck, S. Evidenzbasierte Praxis. In Handlexikon Lernschwierigkeiten und Verhaltensstörungen; Heimlich, U., Stein, R., Wember, F.B., Eds.; Kohlhammer: Stuttgart, Germany, 2013; pp. 247-249.

13. Beushausen, U. Chancen und Risiken einer evidenz-basierten Sprachtherapie. Logos 2014, 22, 96-104.

14. Schlosser, R.W.; Raghavendra, P. Evidence-based practice in augmentative and alternative communication. Augment. Altern. Commun. 2004, 20, 1-21. [CrossRef]

15. Richardson, W.; Scott, M.D.; Wilson, M.C.; Nishikawa, J.; Hayward, R.S.A. The well buildt clinical question: A key to evidence based decisions (Editorial). Am. Coll. Phys. J. Club 1995, 123, A12-A13. [CrossRef]

16. Simons, H.; Kushner, S.; Jones, K.; James, D. From evidence-based practice to practice-based evidence: The idea of situated generalization. Res. Pap. Educ. 2003, 18, 347-364. [CrossRef]

17. Fuchs, L.S.; Fuchs, D.; Malone, A.S. The Taxonomy of Intervention Intensity. Teach. Except. Child. 2017, 50, 35-43. [CrossRef]

18. Cook, B.G.; Tankersley, M.; Cook, L.; Landrum, T.J. Evidence-based practices in special education: Some practical considerations. Interv. Sch. Clin. 2008, 44, 69-75. [CrossRef]

19. Simpson, R.L.; LaCava, P.G.; Graner, P.S. The no child left behind act: Challenges and implications for educators. Interv. Sch. Clin. 2004, 40,67-75. [CrossRef]

20. What Is Scientifically Based Research? A Guide for Teachers. Available online: http://lincs.ed.gov/publications/ pdf/science_research.pdf (accessed on 12 March 2019).

21. Davies, P. What is evidence-based education? Br. J. Educ. Stud. 1999, 74, 108-121. [CrossRef]

22. Odom, S.L.; Brantlinger, E.; Gersten, R.; Horner, R.H.; Thompson, B.; Harris, K.R. Research in Special Education: Scientific Methods and Evidence-Based Practices. Except. Child. 2005, 71, 137-148. [CrossRef]

23. Koch, K. Förderung mathematischer Kompetenzen. In Sonderpädagogische Förderprogramme im Vergleich. Orientierungshilfen für die Praxis; Fingerle, M., Ellinger, S., Eds.; Kohlhammer: Stuttgart, Germany, 2008; pp. 85-108.

24. Hillenbrand, C. Evidenzbasierung sonderpädagogischer Praxis: Widerspruch oder Gelingensbedingung? Z. Für Heilpädagogik 2015, 66, 312-324.

25. Strathmann, A. Denk Dich Fit; Wehrfritz: Bad Rodach, Germany, 2014.

26. Krajewski, K.; Nieding, G.; Schneider, W. Mengen, Zählen, Zahlen. Die Welt der Mathematik Verstehen; Cornelsen: Berlin, Germany, 2007.

27. Schulte-Körne, G.; Mathwig, F. Das Marburger Rechtschreibtraining, 4th ed.; Winkler: Bochum, Germany, 2009. 
28. Motsch, H.-J. Kontextoptimierung. Evidenzbasierte Intervention bei Grammatischen Störungen in Therapie und Unterricht, 3rd ed.; Reinhardt: München, Germany, 2010.

29. Hillenbrand, C.; Hennemann, T.; Hens, S. Lubo aus dem All! Programm zur Förderung Emotional-Sozialer Kompetenzen in der Schuleingangsphase; Reinhardt: München, Germany, 2010.

30. Hartke, B.; Vrban, R. Schwierige Schüler: 49 Handlungsmöglichkeiten bei Verhaltensauffälligkeiten, 3rd ed.; Persen: Buxtehude, Germany, 2014.

31. Grüne Liste Prävention. Auswahl- und Bewertungskriterien für die CTC-Programm-Datenbank. Available online: http://www.gruene-liste-praevention.de/communities-that-care/Media/_Grne_Liste_ Kriterien.pdf (accessed on 12 March 2019).

32. Kriterienliste zur Wissenschaftlich Begründeten Materialauswahl im Mathematikunterricht der Grundschule. Available online: https://www.rim.uni-rostock.de/fileadmin/uni-rostock/Alle_PHF/RIM/ Downloads/KriterienkatalogZurMaterialauswahl-Mathematik_VossSikoraHartke_01.pdf (accessed on 12 March 2019).

33. Kriterienliste zur Wissenschaftlich Begründeten Materialauswahl im Deutschunterricht der Grundschule. Available online: https:/www.rim.uni-rostock.de/fileadmin/uni-rostock/Alle_PHF/RIM/Downloads/ KriterienkatalogZurMaterialauswahl-Deutsch_DiehlVossSikoraHartke_01.pdf (accessed on 12 March 2019).

34. Oxford Centre for Evidence-Based Medicine. Evidenzhierarchie des Oxford Centre for Evidence-Based Medicine. 2009. Available online: https://www.cebm.net/2009/06/oxford-centre-evidence-based-medicinelevels-evidence-march-2009 (accessed on 12 March 2019).

35. Ahrbeck, B.; Ellinger, S.; Hechler, O.; Koch, K.; Schad, G. Evidenzbasierte Pädagogik. Sonderpädagogische Einwände; Kohlhammer: Stuttgart, Germany, 2016.

36. Koch, K. Ankunft im Alltag-Evidenzbasierte Pädagogik in der Sonderpädagogik. In Evidenzbasierte Pädagogik. Sonderpädagogische Einwände; Ahrbeck, B., Ellinger, S., Hechler, O., Koch, K., Schad, G., Eds.; Kohlhammer: Stuttgart, Germany, 2016; pp. 9-41.

37. Ahrbeck, B. ADHS und Evidenzbasierung. In Evidenzbasierte Pädagogik. Sonderpädagogische Einwände; Ahrbeck, B., Ellinger, S., Hechler, O., Koch, K., Schad, G., Eds.; Kohlhammer: Stuttgart, Germany, 2016; pp. 84-99.

38. Hechler, O. Evidenzbasierte Pädagogik-Von der verlorenen Kunst des Erziehens. In Evidenzbasierte Pädagogik. Sonderpädagogische Einwände; Ahrbeck, B., Ellinger, S., Hechler, O., Koch, K., Schad, G., Eds.; Kohlhammer: Stuttgart, Germany, 2016; pp. 42-83.

39. Ellinger, S. Ökonomisierung plus Inklusion = Evidenzbasierte Pädagogik? In Evidenzbasierte Pädagogik. Sonderpädagogische Einwände; Ahrbeck, B., Ellinger, S., Hechler, O., Koch, K., Schad, G., Eds.; Kohlhammer: Stuttgart, Germany, 2016; pp. 100-128.

40. Harn, B.; Parisi, D.; Stoolmiller, M. Balancing fidelity with flexibility and fit: What do we really know about fidelity of implementation in schools? Except. Child. 2013, 79, 181-193. [CrossRef]

41. Kulawiak, P.R.; Wilbert, J. Komplementäre Studiendesigns zur Evidenzbasierung in der Bildungswissenschaft. In Evidenzbasierte Praxis in den Gesundheitsberufen; Haring, R., Siegmüller, J., Eds.; Springer: Berlin, Germany, 2018; pp. 17-31. [CrossRef]

42. Vandell, D.L.; Hembree, S.E. Peer social and friendship: Independent contributors to children's social and academic adjustment. Merrill-Palmer Q. 1994, 40, 461-477.

43. Greenhalgh, T.; Howick, J.; Maskrey, N. Evidence based medicine: A movement in crisis? Br. Med J. 2014, 348, g3725. [CrossRef] [PubMed]

(C) 2019 by the authors. Licensee MDPI, Basel, Switzerland. This article is an open access article distributed under the terms and conditions of the Creative Commons Attribution (CC BY) license (http://creativecommons.org/licenses/by/4.0/). 